\title{
Study on the Influence of Mental Health Course on the Mental Health Level of College Students
}

\author{
Jihui Yue1, Qing Wu${ }^{2}$, Jiazhen $\mathrm{Li}^{1}$, Shenglin Wen ${ }^{1 *}$ \\ ${ }^{1}$ Department of Psychiatry of The Fifth Affiliated Hospital of Sun Yat-sen University, Zhuhai, China \\ ${ }^{2}$ Teaching Department of The Fifth Affiliated Hospital of Sun Yat-sen University, Zhuhai, China \\ Email: *wenshl@mail.sysu.edu.cn
}

How to cite this paper: Yue, J. H., Wu, Q. Li, J. Z., \& Wen, S. L. (2019). Study on the Influence of Mental Health Course on the Mental Health Level of College Students. Creative Education, 10, 3286-3292. https://doi.org/10.4236/ce.2019.1013251

Received: November 12, 2019

Accepted: December 2, 2019

Published: December 5, 2019

Copyright () 2019 by author(s) and Scientific Research Publishing Inc. This work is licensed under the Creative Commons Attribution International License (CC BY 4.0).

http://creativecommons.org/licenses/by/4.0/

(c) (i) Open Access

\begin{abstract}
Objective: To explore the influence of mental health course on the mental health level of college students. Method: To organize psychiatrists or psychotherapists to give lectures on college students' mental health by comprehensive teaching methods, and to evaluate the teaching effect by Symptom Check List, Connor Davidson Resilience Scale and Positive and Negative Affect Schedule. Result: 1) The scores of interpersonal sensitivity, diet and sleep factors are significantly lower than those before teaching, with statistical significance difference. 2) The scores of resilience, strength and optimism are significantly higher than those before teaching, with statistical significance difference. 3 ) The positive emotions grow while the negative emotions are lower after teaching, without statistical significance difference. Conclusion: The mental health course is of positive significance for improving the mental health level of college students, which is worth popularizing.
\end{abstract}

\section{Keywords}

College Students, Mental Health Education, Symptom Check List, Connor Davidson Resilience Scale, Positive and Negative Affect Schedule

\section{Introduction}

In recent years, great studies show that the mental health of college students is worrying (Song et al., 2016). According to the investigation on the psychological problems of college students in China, it is found that about $10 \%-30 \%$ of them have psychological problems (Song et al., 2016; Yao, 2014), which are mainly manifested in professional learning, interpersonal communication, love and sex affair, future employment, adaptation to the campus environment, etc. ( $\mathrm{Lu} \&$ ${ }^{\star}$ Corresponding author. 
Sun, 2017). The course of mental health education is helpful to improve the level of mental health of college students (Cai, 2009). Although numerous colleges and universities in our country have set up mental health education courses for college students, the teaching effect is not ideal because of the abstract psychological knowledge, the lack of suitable teachers, the outdated teaching methods and the low participation of students. To improve the mental health level of college students, the mental health education courses should analyze the problems of college students from the perspective of psychology, so that students can see the essence through the phenomenon, thus better updating the problems. However, due to the fact that the psychological knowledge itself is featured by boring, obscure, abstract, and difficult to understand, therefore, the simple explanation on the theory will be definitely made the classroom teaching uninteresting, boring, and unattractive, which will lead to the decrease of students' participation and interest in learning. Finally, the course will come to an end by becoming a mere formality. Hence, the Fifth Affiliated Hospital of Sun Yat-sen University, aimed at the common psychological problems of college students, boring and unintelligible course content, students' low interest and low participation, adopts the comprehensive teaching method, that is, the teaching teachers acted by the psychiatrists or psychotherapists who have the attending physician and above and obtained the teacher qualification certificate explain systematically via combining clinical cases and problem-orientation, and evaluate through the psychological measurement tools, so as to explore a more suitable teaching method of mental health course.

\section{Course Features}

\subsection{Teaching Content}

On the basis of the common psychological problems of college students, the course has 13 chapters with 32 class hours. Specifically, it includes: introduction, life education, self-awareness, emotional management, learning and mental health, adaptation and mental health, stress and stress coping, sex psychology and mental health, love and mental health, interpersonal communication and adaptation, career planning, recognition and handling of common mental problems of college students, psychological crisis and intervention.

\subsection{Faculty}

The lecturers are attending or above seven doctors and two psychotherapists who have rich clinical experience and obtained the teacher qualification certificate from the teaching and research section of psychiatry of the Fifth Affiliated Hospital of Sun Yat-sen University. They have accumulated a large number of clinical cases in clinical reception, which can ensure the quality and authenticity of the cases used in teaching.

\subsection{Teaching Object}

The teaching object is the undergraduates of Sun Yat-sen University, mainly the 
sophomores. The courses are mainly taught in small classes, with 50 students/class/year. The subjects of this study are 150 college students who took the course of mental health education from 2016 to 2018. 150 questionnaires were sent out, 150 were recovered with $100 \%$ recovery rate, among which 139 were effective questionnaires, with $92.7 \%$ effective rate. The age distribution of the respondents was 18 - 21 years old. Among them, 66 were male, accounting for $47.5 \%$, with an average age of $19.00 \pm 0.80 ; 73$ were female, accounting for $52.5 \%$, with an average age of $19.26 \pm 0.86$.

\subsection{Teaching Method}

Using the comprehensive teaching method, each chapter is explained in the form of "throwing out questions + introducing basic knowledge + combining clinical cases". For example, when teaching the introduction, the concept of "health" is required to introduce. First, the teacher needs to ask the question of "are you healthy?", interact with students with examples that are easy to understand, obvious but not paid attention to, to inspire students to think, and introduce the concept of "health" to discuss with cases depending on the connotation and extension of the concept, for example, the concept of "health" includes moral health, whether the situation of "benefiting oneself at other people's cost" belongs to "health", etc.

\subsection{Evaluation on Teaching Effect}

In order to evaluate the possible influence of the course teaching on the mental health level of college students, 139 subjects are assessed with three psychological test scales before and after teaching.

1) Symptom Check List 90 (SCL-90): in this study, SCL-90, which is widely used in China, is used to test mental health. There are 90 items in this table, including a wide range of psychopathology contents, such as feeling, emotion, thinking, consciousness, behavior to living habits, interpersonal sensitivity, others (i.e. diet and sleep), etc. Each item adopts a 5-grade scoring system. The higher the score is, the more serious the symptom is. Scoring standard: the score of symptom index between 1 and 1.5 indicates that the subjects have no symptoms listed in the scale; between 1.5 and 2.5 indicates that the subjects has slight symptoms, with not frequent occurrence; between 2.5 and 3.5 indicates that the subjects has symptoms, with light to moderate severity; between 3.5 and 4.5 indicates that the subjects has symptoms, with moderate to serious grade; between 4.5 and 5 indicates that the subjects has symptoms, with serious frequency and intensity (Wang, 1984). In this study, Cronbach's a coefficient of each factor is 0.81 on average.

2) Connor Davidson Resilience Scale (CD-RISC): the Chinese version of Connor Davidson Resilience Scale revised by Xiao Nan and Zhang Jianxin in 2007 is applied. There are 25 items in the scale, including three dimensions of resilience, self-improvement and optimism, in the form of 5-grade score system, 
among which 0 means very inconsistent, 4 means very consistent, the higher the score is, the higher the psychological resilience is (Lei, Chen, \& Chen, 2008; Li, 2018). In this study, the Cronbach's a coefficients of the three scales are 0.88 on average.

3) Positive and Negative Affect Schedule (PANAS): this scale has two dimensions, a total of 18 items, including 9 positive and negative affect items, using 5-point scoring system, from "no" to "very strong", respectively recording $1,2,3,4,5$ points. The higher the score is, the more positive or negative emotions the subject experience (Chen \& Zhang, 2004). In this study, Cronbach's $\alpha$ is 0.78 .

\subsection{Statistical Method}

The database is established with Epi Data 3.02 Software to perform double input and logical check. SPSS 20.0 statistical software is used to test the experimental data, $\bar{x} \pm s$ is used to express normal measurement data, and Student's test and Pearson correlation analysis are used to compare the measurement data before and after the lecture. $\mathrm{P}<0.05$ is statistically significant.

\section{Result}

\subsection{Score of SCL}

The scores of interpersonal sensitivity, diet and sleep factors of students after teaching are lower than those before teaching with statistical significance difference, and the scores of other factors are lower than those before teaching, indicating that the intervention measures are effective, but the difference is not statistically significant, showing that through the study of the course, it is of positive significance to improve the factors related to emotion, such as depression, anxiety, terror, hostility, etc., and grate significance to interpersonal sensitivity, diet, sleep and other factors. See Table 1 for specific results.

\subsection{Score of CD-RISC}

The scores of tenacity, strength and optimism in psychological resilience after teaching are higher than those before, with statistical significance difference, which shows that the course is conducive to improving the level of psychological resilience of college students. See Table 2 for specific results.

\subsection{Score of PANAS}

By comparing the changes of college students' emotions before and after teaching, it is found that the positive emotions increase while the negative emotions decrease, but the difference is not statistically significant, showing that suggests that the intervention of this course may have a positive effect on improving college students' positive emotions, but the results are not statistically significant, so this effect is still necessary for further observation. See Table 3 for specific results. 
Table 1. Comparison of scores of SCL before and after teaching.

\begin{tabular}{ccccc}
\hline Item & $\begin{array}{c}\text { Before Intervention } \\
(\bar{x} \pm s)\end{array}$ & $\begin{array}{c}\text { After Intervention } \\
(\bar{x} \pm s)\end{array}$ & $t$ value & $P$ value \\
\hline Somatization & $1.58 \pm 0.84$ & $1.56 \pm 0.69$ & 0.21 & 0.835 \\
Force & $1.96 \pm 0.66$ & $1.86 \pm 0.52$ & 1.59 & 0.125 \\
Interpersonal sensitivity & $2.10 \pm 0.62$ & $1.87 \pm 0.71$ & 2.29 & $0.031^{*}$ \\
Depression & $1.96 \pm 0.70$ & $1.84 \pm 0.66$ & 1.21 & 0.239 \\
Anxiety & $1.85 \pm 0.62$ & $1.72 \pm 0.67$ & 1.70 & 0.102 \\
Hostility & $1.88 \pm 0.66$ & $1.73 \pm 0.84$ & 0.84 & 0.407 \\
Terror & $1.48 \pm 0.51$ & $1.47 \pm 0.48$ & 0.10 & 0.922 \\
Paranoia & $1.67 \pm 0.59$ & $1.69 \pm 0.60$ & -0.21 & 0.832 \\
Psychosis & $1.81 \pm 0.48$ & $1.82 \pm 0.60$ & -0.05 & 0.963 \\
Other & $1.87 \pm 0.58$ & $1.53 \pm 0.41$ & 6.76 & $0.001^{*}$ \\
\hline
\end{tabular}

Table 2. Comparison of scores of CD-RISC before and after teaching.

\begin{tabular}{ccccc}
\hline Item & Before Intervention $(\bar{x} \pm s)$ & After Intervention $(\bar{x} \pm s)$ & $t$ value & $P$ value \\
\hline Tenacity & $38.07 \pm 6.05$ & $39.56 \pm 6.32$ & -2.13 & $0.040^{*}$ \\
Strength & $22.51 \pm 4.90$ & $23.74 \pm 4.60$ & -2.57 & $0.014^{*}$ \\
Optimism & $12.72 \pm 2.43$ & $13.64 \pm 2.07$ & -3.38 & $0.002^{*}$ \\
\hline
\end{tabular}

Table 3. Comparison of scores of PANAS before and after teaching.

\begin{tabular}{ccccc}
\hline Item & Before Intervention $(\bar{x} \pm s)$ & After Intervention $(\bar{x} \pm s)$ & $t$ value & $P$ value \\
\hline Positive affect & $26.49 \pm 7.78$ & $29.31 \pm 7.92$ & 0.22 & 0.828 \\
Negative affect & $27.77 \pm 7.13$ & $26.88 \pm 8.69$ & 0.68 & 0.502 \\
\hline
\end{tabular}

\section{Conclusion}

\subsection{The Course of Mental Health Education for College Students Is Helpful to Improve Their Mental Health Level}

This course takes the most common psychological problems of medical college students as the core to set the content, introduces the course in the way of clinical cases, combines a large number of clinical cases in the process of explanation, analyzes and explains the problems from multiple perspectives, introduces the basic theoretical knowledge of psychology, guides students to actively participate in the course cases through on-site demonstration, and comments after discussion, so that students can experience and learn how to interpret problems, analyze problems, and finally achieve the goal of problem solving from the perspective of psychology. The quantitative evaluation of the teaching effect by SCL-90, CD-RISC and PNANS suggests that the psychological symptoms, psychological resilience and positive emotions of college students are improved compared with those before the teaching, which achieves the purpose of the course. By means of comprehensive analysis, it is considered that the following may be relevant: 
1) Suitable Faculty. The course teachers are psychiatrists or psychotherapists with rich clinical experience, who have accumulated a large number of real and practical clinical cases related to students' mental health, which are more infectious, and can evoke resonate with students. In addition, teachers can skillfully apply psychotherapy technology to classroom teaching, such as listening technology, so that students can feel that they are understood, concerned and be willing to open their hearts to talk about their views in class. Consequently, psychiatrists or therapists with rich clinical experience are the key to achieve quality results in this course.

2) Comprehensive Teaching Methods. This course, based on lecturing, problem-orientation, and a large number of clinical cases, applies psychological consultation technology to mobilize students' enthusiasm, trigger students' thinking, and promote the establishment of students' reasonable cognition; and intersperses the role-playing, group discussion and other empirical teaching modes to let students actively participate. Because of the integration of a variety of teaching methods, the classroom atmosphere is active, so that everyone can learn and grow in happiness. Therefore, through years of teaching experience summary on college students' mental health education, the course may need to integrate a variety of teaching modes to achieve more excellent results.

\subsection{Limitations of This Course}

There are still some shortcomings in this course. First, large number of teachers. Due to the fact that a large number of psychological consultation technology is integrated into the teaching process, there will be different interpretations of some issues and a certain degree of conflict because of the different schools of psychology of each teacher, and students' feedback on each teacher and the whole teaching effect has not been collected. The overall mental health level of students has been improved, however, it still needs for further exploration in terms of integrating the teaching staff and improving the teaching level. Second, the traditional teaching mode is dominated by lecture and large class teaching, while the integrated teaching of small class is adopted at the beginning of the course setting, so it is impossible to compare the teaching effect of the traditional teaching mode with that of the course. Even so, the course is set for 50 students per class, but there are still too many students in the teaching process, and there are students who are not taken into account in mobilizing enthusiasm. Moreover, it is generally believed that the mental health level of college students will be improved to a certain extent after they adapt to school life, but this study has not carried out a horizontal control study, so it is necessary to include the horizontal study into the next step for comparison. Third, the teachers of this course are all clinical teachers, there is lack of comparison of teaching effect of non clinical teachers, so it is impossible to know whether there are differences in different types of teachers using the same teaching method. Therefore, in the future, teaching reform will be carried out in view of the above problems to explore a 
more suitable teaching mode.

\section{Author's Contribution Statement}

Wen Shenglin in charge for project overall design, Yue Jihui in charge for project design, data collection, statistics and paper writing; Wu Qing in charge for statistics, paper review, polish; Li Jiazhen in charge for data sorting and input.

\section{Conflicts of Interest}

All authors declare that there is no conflict of interest.

\section{References}

Cai, H. (2009). Thoughts and Suggestions on Setting up Mental Health Courses for College Students in Medical Schools. Chinese Journal of Medical Education Research, 8, 1055-1057

Chen, W. F., \& Zhang, J. X. (2004). Structure and Validity on Chinese Version of Positive and Negative Affect Schedule. Chinese Mental Health Journal, No. 11, 763-765, 759.

Lei, W. S., Chen, X., \& Chen, J. T. (2008). Study on the Psychological Resilience of College Students. China Journal of Health Psychology, No. 2, 155-157.

Li, L. M. (2018). A Review of the Research on Psychological Resilience of College Students. Yangtze River Series, No. 17, 248, 260.

Lu, K. Z., \& Sun, Q. B. (2017). Study on Mental Health Problems and Countermeasures of College Students. Health Vocational Education, 35, 156-158.

Song, H. Y. et al. (2016). Investigation and Analysis of Mental Health Status of College Students after 1990's-Taking University of South China in Hengyang City, Hunan Province as an example. Journal of Qufu Normal University (Natural Science), 42, 101-104.

Wang, Z. Y. (1984). Symptom Check List 90 (SCL-90). Shanghai Archives of Psychiatry, No. 2, 68-70.

Yao, E. J. (2014). An Analysis of Mental Health Status of Independent College Students in Five Colleges and Universities in Henan Province. Chinese Journal of Health Education, 30, 1105-1107, 1120 . 